Review

\title{
Mission Shakti aka Project XSV-1: India's First Anti-Satellite Test (ASAT)
}

\author{
Santosh Kosambe \\ Independent Researcher, Pune, India
}

Article history

Received: 29-05-2019

Revised: 21-06-2019

Accepted: 23-07-2019

Email: santo2040@gmail.com

\begin{abstract}
The Mission Shakti, also called as Project XSV-1 was India's first Anti-Satellite Test (ASAT) conducted successfully on 27 March 2019. The PDV-MK II interceptor missile designed and developed by Defence Research and Development Organisation (DRDO) was launched from Dr A.P.J. Abdul Kalam Island to intercept the Microsat-R satellite. The Microsat-R satellite, which acts as a prime target for the mission was India's imaging satellite manufactured by DRDO and launched into the orbit eight weeks before the test by Indian Space Research Organisation (ISRO). The Project XSV-1 had been under planning since 2016. As India's space programme is rapidly growing, its nation's responsibility to safeguard the country's assets present in outer space. Also, the nation is concerned about the threats it faces in outer space; the ASAT test was conducted to examine the capability of the nation to defend itself in space. The mission was planned at the lowest possible altitude to avoid any risk to the operational space assets. India has demonstrated its capability to legitimate deterrence against increasing threats to nations emerging space assets from various kinds of missiles. With this particular successful test, India becomes the fourth country among an exclusive group of space-faring nations to perform ASAT. The paper provides an overview of the overall Mission Shakti, aka Project XSV-1.
\end{abstract}

Keywords: Mission Shakti, Project XSV-1, DRDO, ASAT, PDV-MK II

\section{Introduction}

According to the United Nations Institute for Disarmament Research (UNIDIR), Anti-Satellite missiles are space missiles intended to incapacitate, disable or destroy space assets whether military or civilian, offensive or defensive for strategic military purposes. The ASAT weapons are commonly categorized into two kinds; one is Kinetic and another one is Non-Kinetic. Kinetic missiles physically strike an object in space intending to destroy both object and target. These include ballistic missiles or drones that can drag a space object out of its orbit or detonate explosives when coming in proximity with an object. Also, it can be any item launched to coincide with the passage of a target satellite. Non-Kinetic missiles use a variety of nonphysical means that can disable or destroy objects in space. These include frequency jamming, blinding lasers or cyber-attacks. These methods additionally possess an ability to render the targeted objects useless without causing them to break up. Several space-faring countries have operational ASAT missiles.
Although none of the countries utilized these missiles in warfare. Only four nations (United States of America, Russia, China and India) have demonstrated the capabilities of ASAT by focusing on their very own satellites orbiting in space. On 27 March 2019, India successfully carried out an ASAT named as Mission Shakti from Dr A.P.J. Abdul Kalam Island, formerly known as Wheeler Island. The Prithvi Defence Vehicle Mark II (PDV-MK II) interceptor missile was launched at 11:09 AM Indian Standard Time (IST) from the Launch Complex-III (LCIII) of Integrated Test Range (ITR) missile testing facility located in Chandipur, Odisha (Fig. 1) The satellite targeted was among India's existing satellite Microsat-R orbiting in Lower Earth Orbit (LEO) at an altitude of $284 \mathrm{~km}$. The orbital position of target satellite at the time of intercept had been within a kilometre of $180.715 \mathrm{~N}, 870.450 \mathrm{E}$ at an altitude of 284 $\mathrm{km}$. The missile struck at the centre of the $740 \mathrm{~kg}$ satellite with the precision of $10 \mathrm{~cm}$ accuracy within 168 seconds of the launch as it traversed northward over the way of Bengal, turning the satellite into debris. 


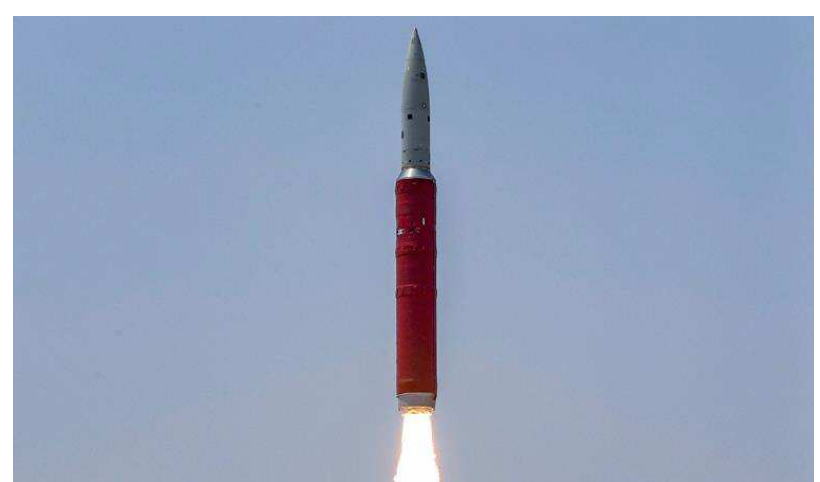

Fig. 1: The PDV-MK II Missile Launched from Dr. A.P.J. Abdul Kalam Launch Complex on 27 March 2019

The PDV-MK II missile was a modified version of DRDO's PDV anti-ballistic interceptor missile, which is a part of the ongoing ballistic missile defence programme. As Space technologies are continually evolving, the nation has developed its capability in kinetic kill technology. The Kinetic Kill Vehicle or Hit to Kill missile was employed to achieve the objectives of the mission by striking and shattering the target satellite. In such a missile, the metal warhead is utilized to break the target satellite with the help of high velocity and impact energy (MEA, 2019).

The Mission Shakti was a technological mission developed and operated by DRDO. The mission was planned at the lowest possible orbit of $284 \mathrm{~km}$, well below the orbit of other space objects to avoid threat of debris to other space assets. The target satellite was also deliberately launched into an orbit of $284 \mathrm{~km}$ to ensure that it remained about $120 \mathrm{~km}$ below the International Space Station (ISS). The interceptor missile was specially designed to strike the satellite at an angle to ensure the creation of minimal debris. The ASAT was successful and attained all the parameters as it needed an incredibly high level of accuracy and technical capability. Soon after the test, DRDO released video of the ASAT test. The video shows the trajectory of the missile before impact with the target satellite and also an explosion of the target after the impact. The importance associated with the test is the fact that India has examined and conclusively demonstrated its capability to interdict and intercept a satellite in outer space based on comprehensive indigenous technology. Because of the test, India has now mastered the technology of BMD and ASAT and joins an exclusive group of space-faring nations, which involves the United States of America, Russia and China.

\section{Recent ASAT Tests}

India's demonstration of ASAT comes after twelve years of China's and almost sixty years after that of the United States of America and Russia. India's ASAT is similar to the U.S. test targeting its own USA-193 military spy satellite. The Table 1 shows the amount of debris generated after the intentional break-up of satellites through ASAT.

\section{ASAT Test of China}

On 11 January 2007, China effectively destroyed its very own defunct weather satellite Fengyun-1C at 22:28 UTC. The missile used in the destruction was SC-19 ASAT missile (Fig. 2) having a kinetic kill warhead which is a modified version of DF-21 ballistic missile. The interceptor missile had been blasted off from a Transporter Erector Launcher (TEL) vehicle located at Xichang Satellite Launch Center. The target for the test, Fengyun-1C weighing $750 \mathrm{~kg}$ was a weather satellite orbiting in Sun Synchronous Polar Orbit of $865 \mathrm{~km}$. The satellite was launched in 1999 and was the fourth satellite in Feng Yun series. The intentional destruction of a satellite at an altitude of $800 \mathrm{~km}$, created over 3000 fragments large enough to be tracked and 150,000 of small fragments. The test ended up being the most significant recorded event for the creation of space debris in history. Since, the test was conducted at higher altitudes and also at an angle, the majority of the debris generated is nevertheless orbiting in space today. According to the estimation from NASA's Orbital Debris Program Office, around 30\% of the larger fragments associated with the test would remain in orbit by 2035 (Covault, 2007).

\section{ASAT Test of United States}

On 20 February 2008, the United States under the Operation Burnt Frost successfully carried out the destruction of a malfunctioned satellite named USA-193 (Fig. 3). The launch took place at 10:26 PM EST from the Warship USS Lake Erie (CG-70), a Ticonderoga Class Guided Missile Cruiser associated with the United States Navy. The missile used in operation was a RIM-161 Standard Missile-3 (SM-3) which is a ship-based missile system utilized to intercept the targets in LEO. The target for the operation was USA-193, also identified as NRO Launch 21 (NROL-21) had been a U.S. Military Reconnaissance Satellite launched on 14 December 2006 with a two-stage Delta-II rocket. About a month after the launch it had been reported that the satellite had failed and had been decaying from its original orbit at a rate of $500 \mathrm{~m}$ each day. Based on the U.S. government, the main reason behind destroying the satellite was the $450 \mathrm{~kg}$ of toxic hydrazine fuel contained on board. The destruction operation of USA193 at an altitude of $240 \mathrm{~km}$ have created 174 fragments large enough to be tracked. The fragments generated due to the test reentered, typically in a month of the test (Webb, 2008). 


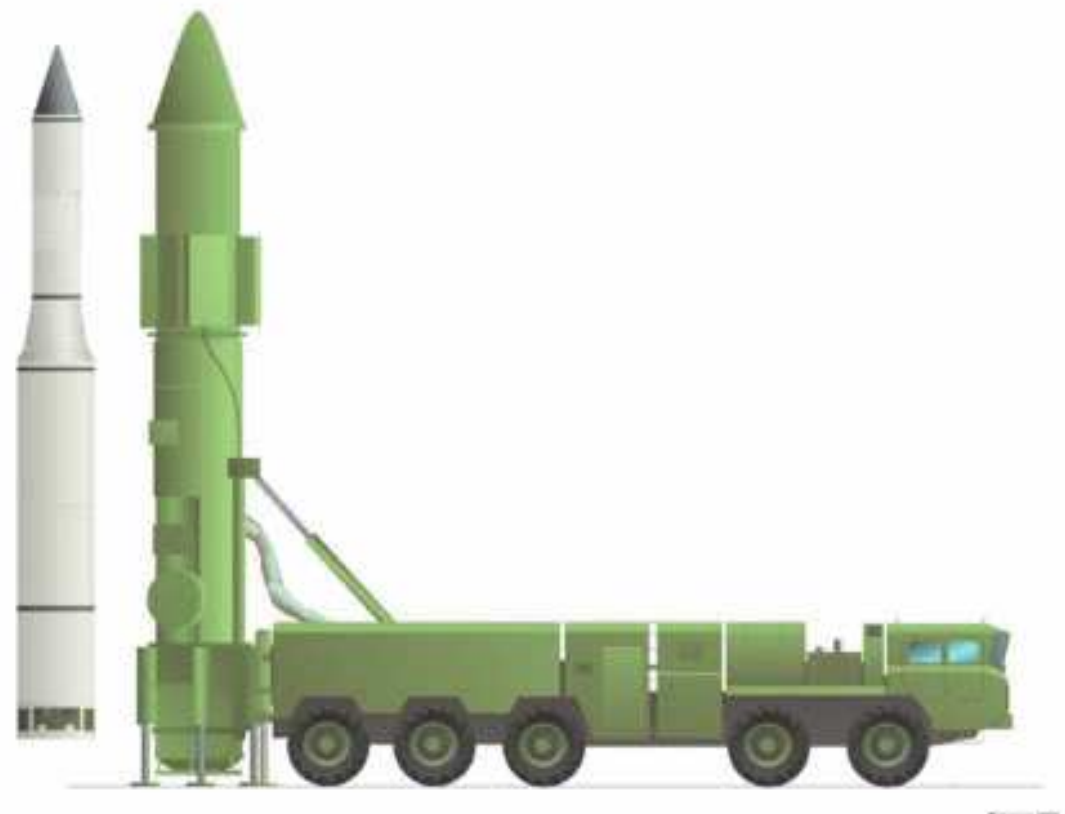

Fig. 2: Chinese SC-19 ASAT Interceptor Missile

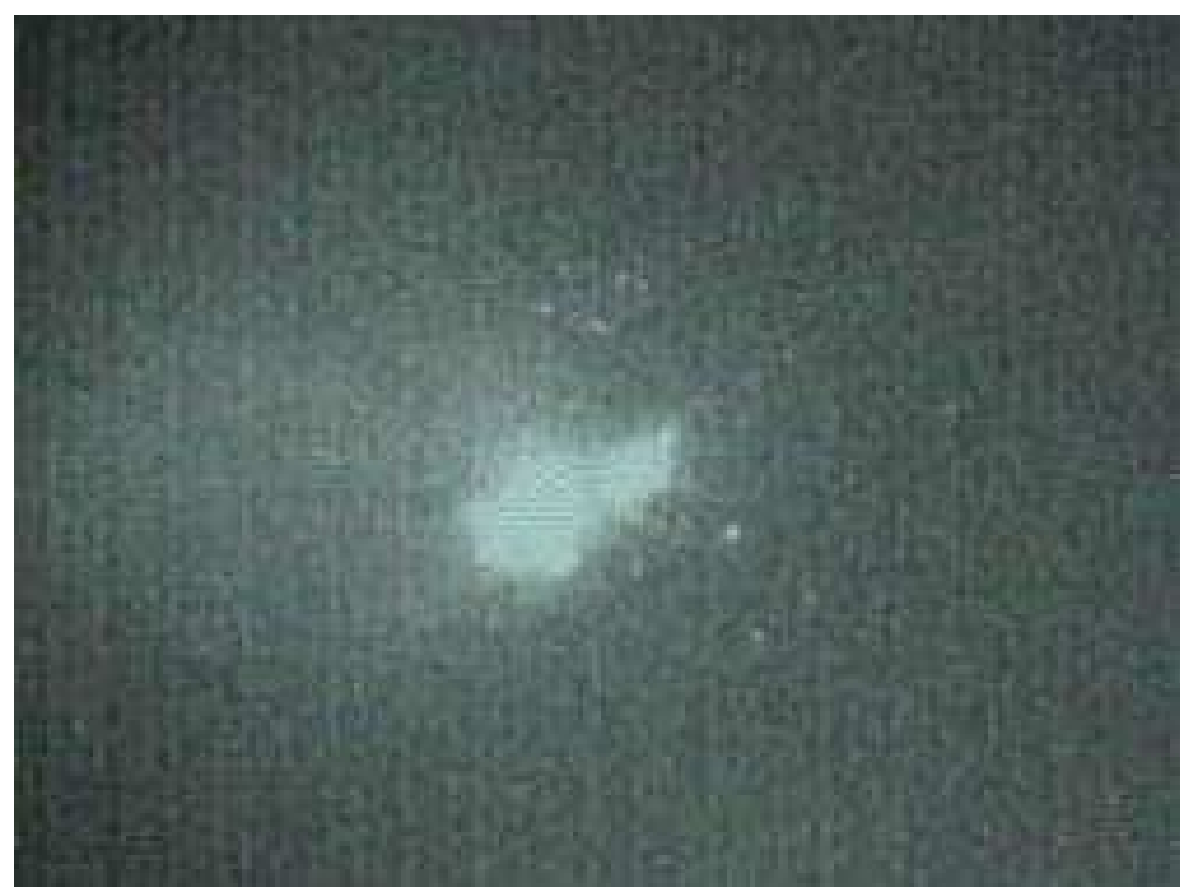

Fig. 3: Breakup of USA 193 after interception of SM-3 Missile

Table 1: List of Recent ASAT Tests. [Source: Secure World Foundation.]

\begin{tabular}{lllllll}
\hline Country & Test date & Target & Interceptor missile & Intercept altitude & Orbital debris & Life span of debris \\
\hline China & January 11, 2007 & FY-1C & SC-19 & $800 \mathrm{~km}$ & 3,000 & Several Decades \\
United States & February 20, 2008 & USA 193 & SM-3 & $240 \mathrm{~km}$ & 174 & 18 Months \\
India & March 27, 2019 & Microsat-R & PDV-MK II & $284 \mathrm{~km}$ & 400 & Weeks-Months \\
\hline
\end{tabular}




\section{ASAT Test of Russia}

On 23 December 2018, Russia conducted another successful test of an ASAT missile under the A-235 PL19 Nudol anti-ballistic missile and anti-satellite weapon program in development. The ASAT missile travelled for seventeen min and almost $3000 \mathrm{~km}$ before splashing straight down its target (Sheetz et al., 2019).

\section{Target for Mission Shakti}

The Microsat- $\mathrm{R}$ with COSPAR designation as 2019006A had been a prime target for Mission Shakti. It was a $740 \mathrm{~kg}$ military imaging satellite manufactured by DRDO. The workhorse of ISRO, Polar Satellite Launch Vehicle (PSLV-C44) launched the satellite into space. The launch of PSLV-C44 took place on 24 January 2019 from First Launch Pad (FPL) at Satish Dhawan Space Centre SHAR, Sriharikota at 23:37 Hrs (IST). About 13 minutes 26 seconds after lift-off, Microsat-R (Fig. 4) had been effectively inserted into Sun Synchronous Polar Orbit of $274 \mathrm{~km}$. The launch marks the 46th flight of PSLV and very first flight of 2019. Additionally, the PSLV-C44 mission was a unique one because of the utilization of the final stage of the vehicle (PS4) as being a platform to conduct experiments in space. After injection, two solar arrays associated with the satellite had been deployed immediately and ISRO's Telemetry Tracking \& Command Network (ISTRAC) at Bengaluru take control of the satellite (ISRO, 2019).

\section{PDV-MK II Missile}

The DRDO stated that, the PDV-MK II (Fig. 5) as being a completely new missile developed specifically for ASAT mission in which some technologies of BMD interceptor were utilized. Additionally, there have been many new technologies part of the first kinetic kill. The missile is a three-stage interceptor having two solid propellant rocket motor stages weighing around 18 tonnes and having a height of 13 meters and a hit to kill capable Kill Vehicle (KV) that has been employed to target the satellite under Mission Shakti. The initial stage of this missile had been separated at $45 \mathrm{~km}$ after lift-off while the second stage gets separated at $110 \mathrm{~km}$. The third stage of the missile travelled another $200 \mathrm{~km}$ to destroy the target satellite. It pulverized the Microsat-R weighing $740 \mathrm{~kg}$ within almost three minutes $(168 \mathrm{sec})$ after the launch. The onboard advanced terminal guidance system, which featured a strap-down non gimbaled Imaging Infrared (IIR) seeker as well as an inertial navigation system used a Ring Laser Gyroscope (RLGs) to identify and track the satellite orbiting in LEO. The two rocket engine stages are used to achieve the desired altitude and velocity. The IIR seeker located within the very front of the nose is used to lock onto the target satellite and guide it towards at a closing speed of almost $10 \mathrm{~km} / \mathrm{s}$. The corrections in the trajectory of the missile were made using a Thrust Vector Control (TVC) system comprising larger thrusters at the top of the missiles cylindrical body at roughly its Centre of Gravity (CG) and small thrusters nearthe rear of the missile. The radar, data and communication links of the DRDO designed BMD systems that were deployed across a wide ground span had effectively tracked the entire satellite interception by the ASAT missile. The ASAT missile's guidance and control algorithm are developed to intercept satellites at an altitude of more than $1200 \mathrm{~km}$ (Anantha, 2019).

\section{Reasons to Conduct ASAT}

The nation includes a well-established and speedily expanding space programme. It has expanded quickly within the last five years. Within the last twenty years, India has progressively and considerately increased its assets in the space domain. India has also completed 105 spacecraft missions comprising of communication satellites, navigation satellites, meteorological satellites, earth observation satellites, experimental satellites. Apart from these, it has also undertaken the interplanetary missions, space exploration missions and missions for educational studies as well. At the moment, India has about fifty operational satellites orbiting in different orbits around the earth. Many of them are communicational, navigational and earth observation satellites. India's space programme is a critical backbone of the nation's security, economic and social infrastructure. Obviously, India has to ensure that it has the capability to safeguard its space assets.

Furthermore, because of geostrategic coercions, the nation felt the necessity to demonstrate the technical abilities pertaining to anti-satellite weapons. Outer space becoming a field of competition amongst nations. The defence and offensive space technologies are being developed with different aims of spying, gaining control, deactivating service and destroying. India's ASAT was also an apparent response to an assessment of these growing threats in the outer space.

India's space and security administrators had an internal discussion on the importance of possible response to demonstrate that they too were a force to be reckoned with. As India sees itself as locked in a regional competition with China for power and prestige, alongside occasional military conflicts along with an unsettled border that risk escalating tensions amongst the two nuclear powers. India also had been concerned with a repeat of history along with it being among the nation not to demonstrate ASAT if there was clearly a future ban on direct-ascent ASAT testing, as India had not tested a nuclear weapon before the Nuclear NonProliferation Treaty and therefore is not considered as being a nuclear weapon state, per treaty language. 


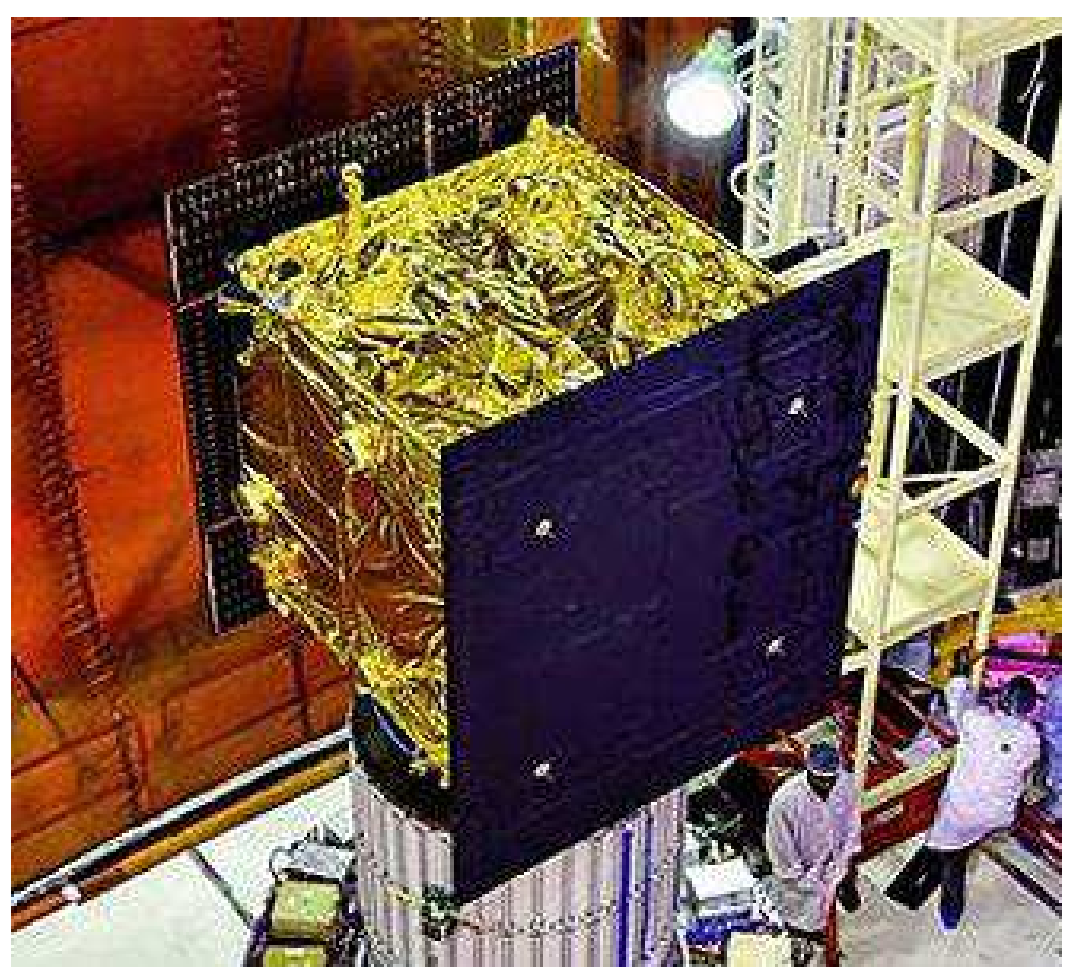

Fig. 4: Target Satellite Microsat-R for ASAT test

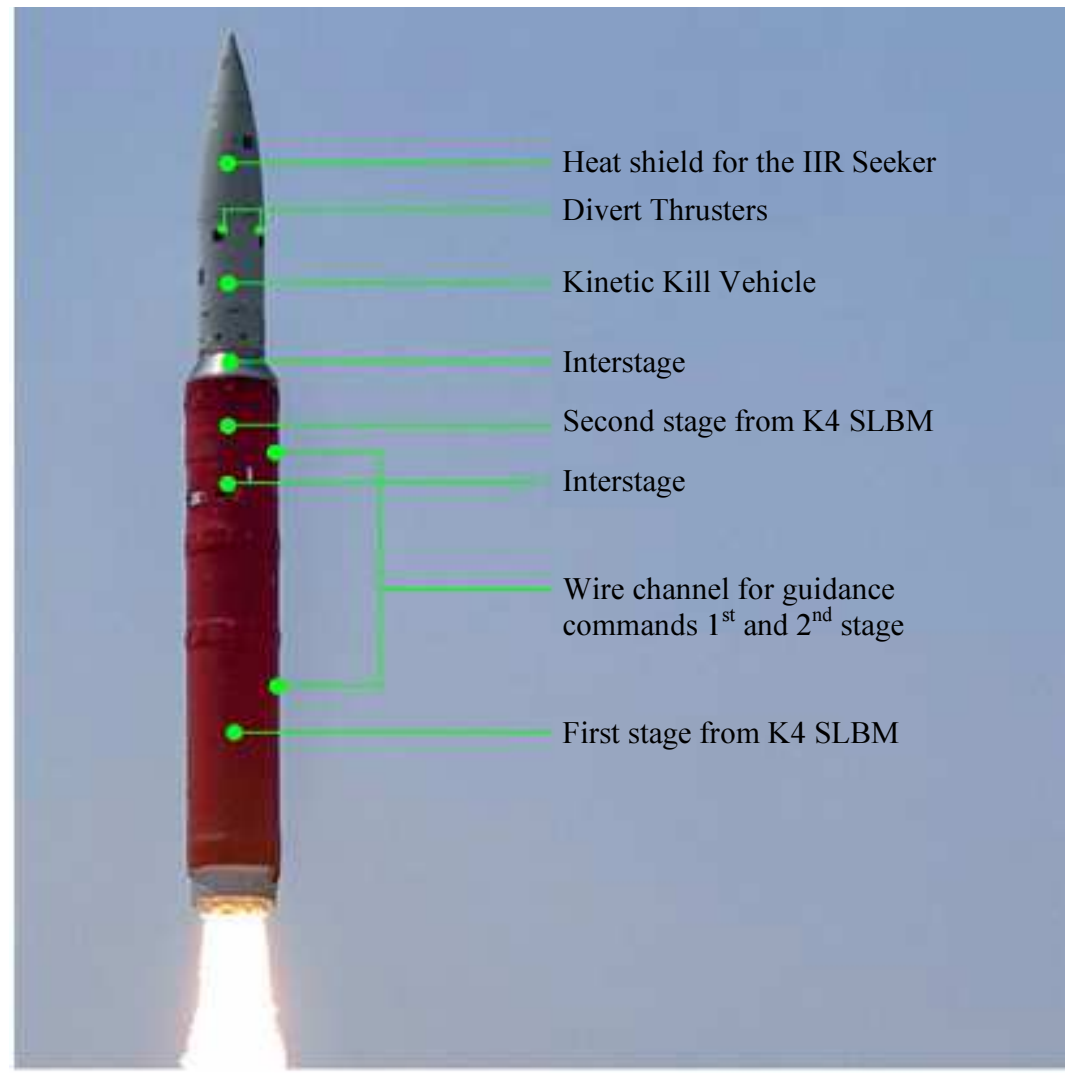

Fig. 5: PDV-MK II Interceptor Missile 
The ability to destroy a satellite plus the creation of an unexpected debris field are significant concerns for many countries that have the space assets in orbit. India's recent testing of its ASAT capability most likely represents a feeling by other countries that the weaponization of space is forthcoming and India does not want to be left out of it if arms-control agreements are eventually reached. And many countries with ASAT capabilities have followed this route, mainly because this might be politically acceptable while other ASATs have not been acceptable. The test had been conducted after the country had developed the required assurance to confirm its success and reflects the intention of India to improve its national security.

Additionally, India's ASAT or any space capabilities do not threaten any country and nor are they directed against anyone. At the same time, India is committed to ensuring the country's national security interests and is aware of threats from growing technologies. The ability accomplished through the ASAT delivers legitimate deterrence against threats to developing space assets from any weapons and missiles. Also, there is a need to take note that India is the only state that has officially announced its ASAT testing. This announcement was made by none other than the Indian Prime Minister himself. The Indian administration released a Frequently Asked Questions
(FAQ) on its website that explained the reasons to conduct an actual intercept rather than less destructive tests within hours of ASAT. The FAQ also clarified the way the test did not change India's position on preventing an arms race in outer space or opposition towards the weaponization of outer space. With the announcement of the mission, it becomes clear that India would like to be transparent in all activities it undertakes in space. Space security is a crucial issue for India (MEA, 2019).

\section{Space Debris Generated}

The ASAT test was carried out at a lower altitude of $284 \mathrm{~km}$ and also at a specific angle to ensure that minimal amount of debris would be created and quickly re-enter into the Earth's atmosphere to avoid any damage to the ISS along with other operational satellites orbiting in LEO. The satellite Microsat-R at a distance of $0.84 \mathrm{~km}$, captured from IIR Camera on a missile is shown in Fig. 6. Although the test has created at least 250 to 400 fragments of orbital debris more significant enough to be tracked. The destruction created fragments along its polar retrograde orbit, inclined $96.7^{\circ}$ with respect to the Earth's equator as the ASAT missile strikes the target with an upwards angle of about $48^{\circ}$ with the horizontal and $135^{\circ}$ with regards to the satellite's motion.

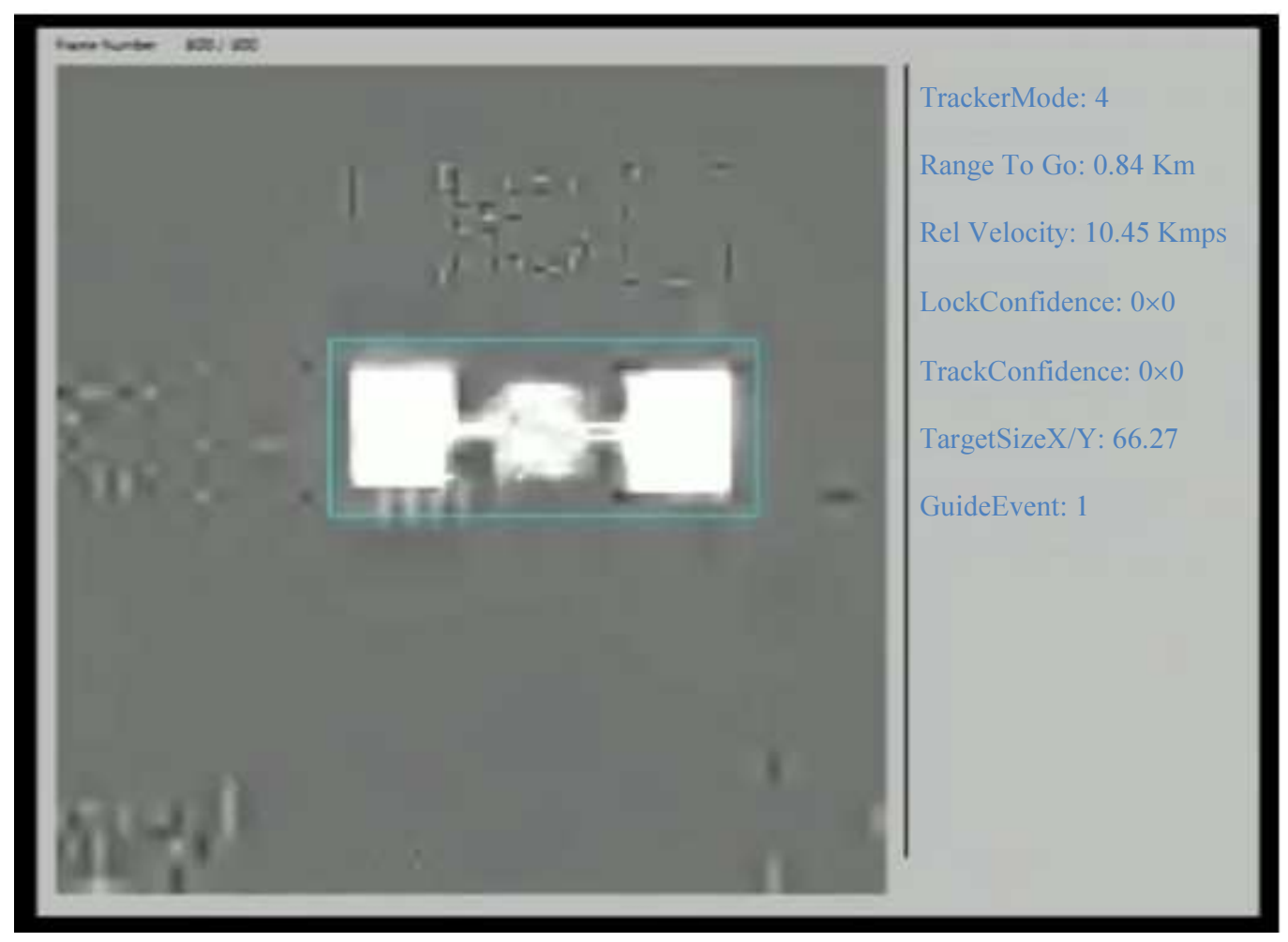

Fig. 6: Still frame of Microsat-R captured by IIR camera on Missile 


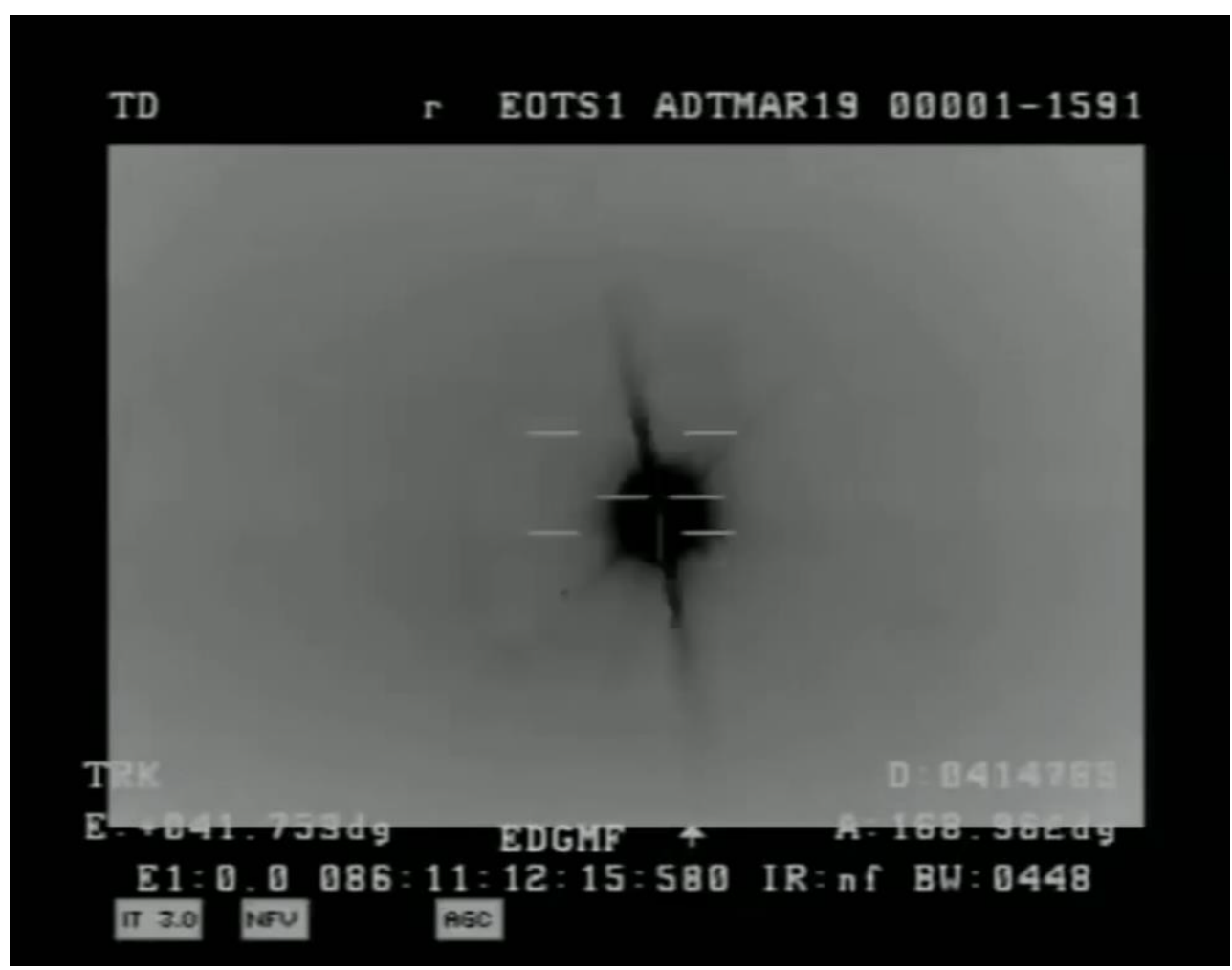

Fig. 7: Still image of the intercept from DRDO video

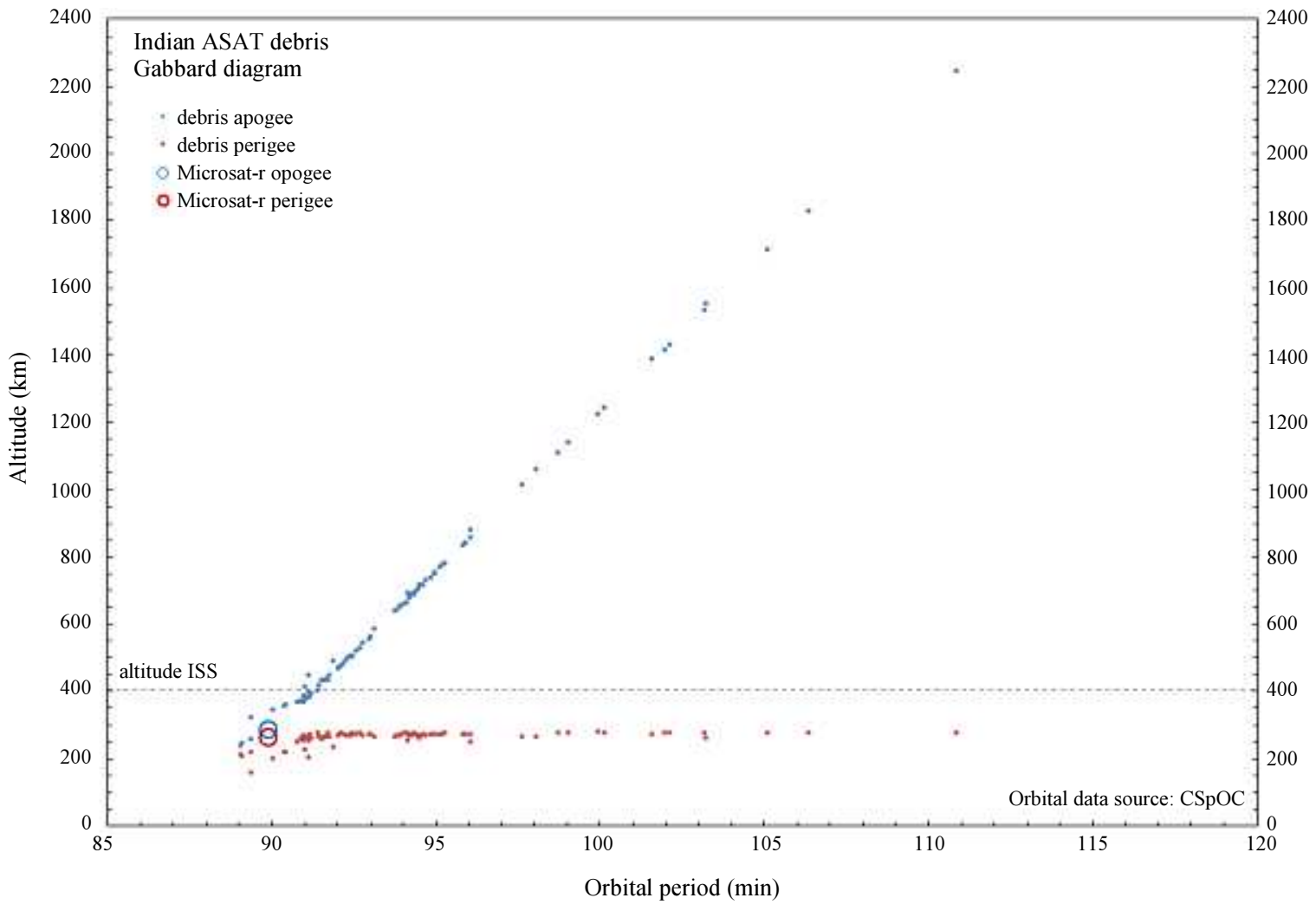

Fig. 8: Gabbard diagram of fragments plotted after ASAT test 


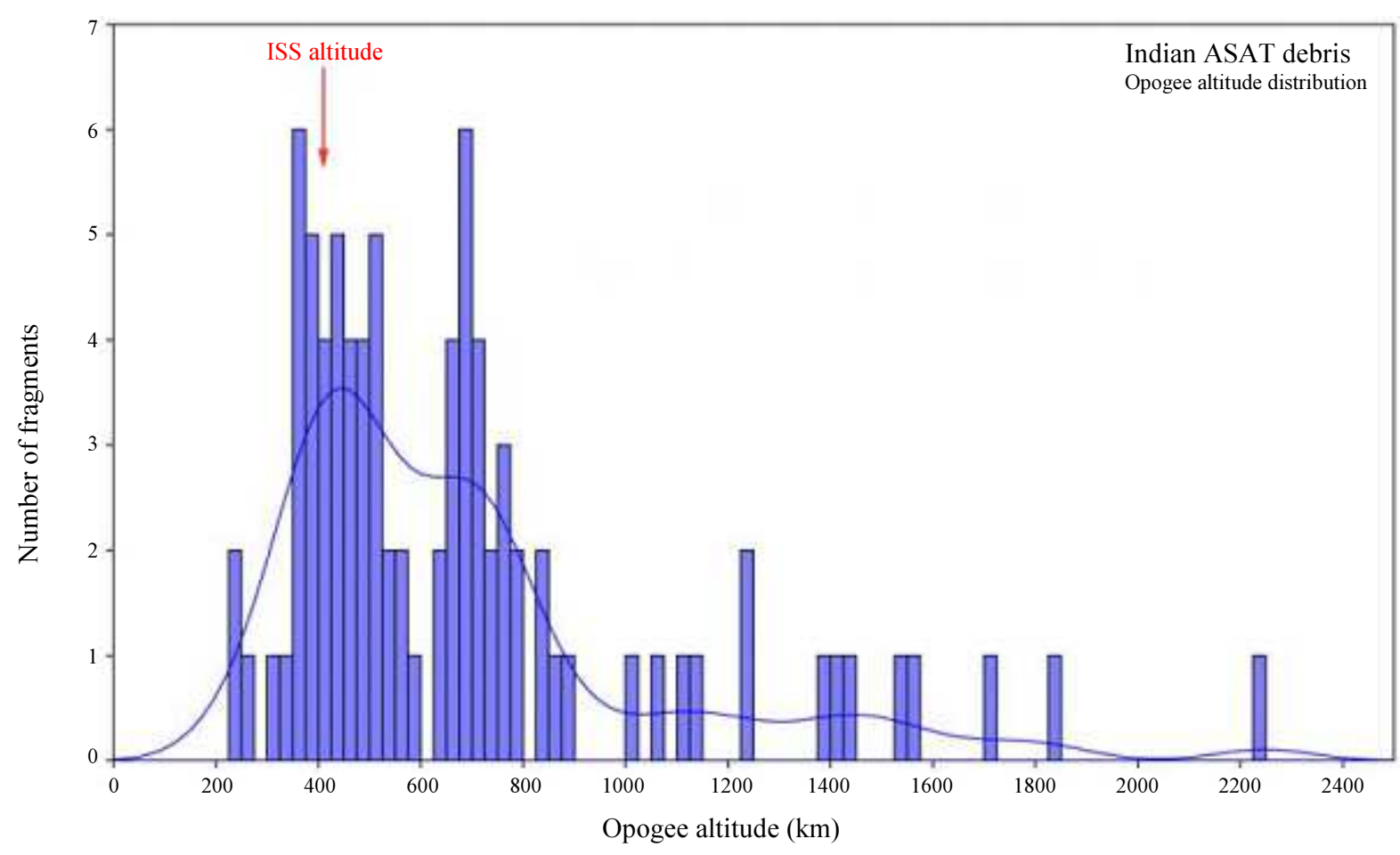

Fig. 9: Distribution of apogee altitudes for debris fragments

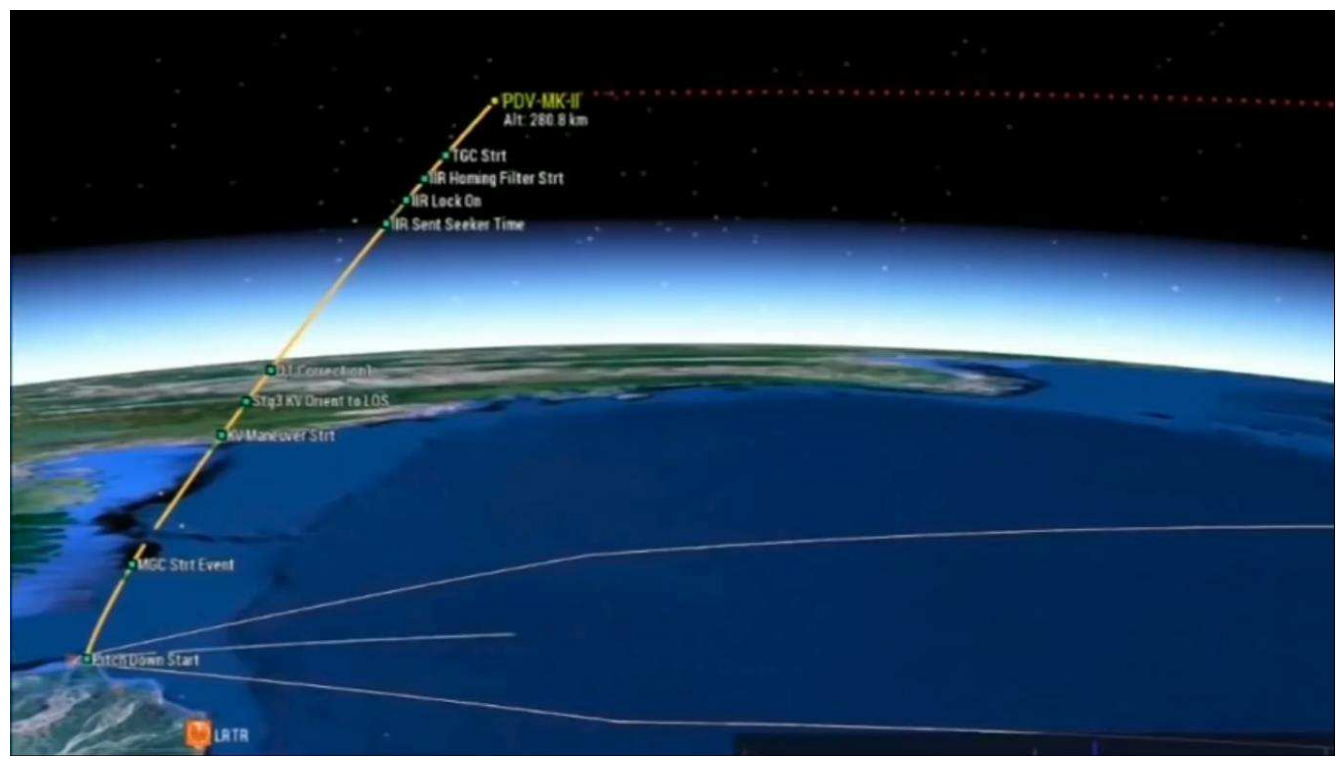

Fig. 10: Still image of graphical representation of missile trajectory captured from DRDO video

A direct impact approaching from underneath raises the threat of fragments being expelled to altitudes over the satellite's initial orbit. The image taken by the Infrared Camera positioned on the Indian Coast as missile intercept the target satellite can be seen in Fig. 7. The missile impacted on a satellite with the relative speed of 10.45 $\mathrm{km} / \mathrm{s}$. Out of total 400 fragments, about eighty-four fragments of debris have already been tracked so far and twenty-four of which may have their apogees over the orbit of the ISS at about $410 \mathrm{~km}$. The Gabbard diagram shown in Fig. 8 shows the lowest point in an elliptical orbit and also the highest point in its orbit, plus it shows duration to accomplish one revolution around the Earth. On 5th April, the United States Combined Space Operation Command (USSPACECOM) shared the initial 84 monitoring fragments after the ASAT under NORAD ID 2019-006A. 


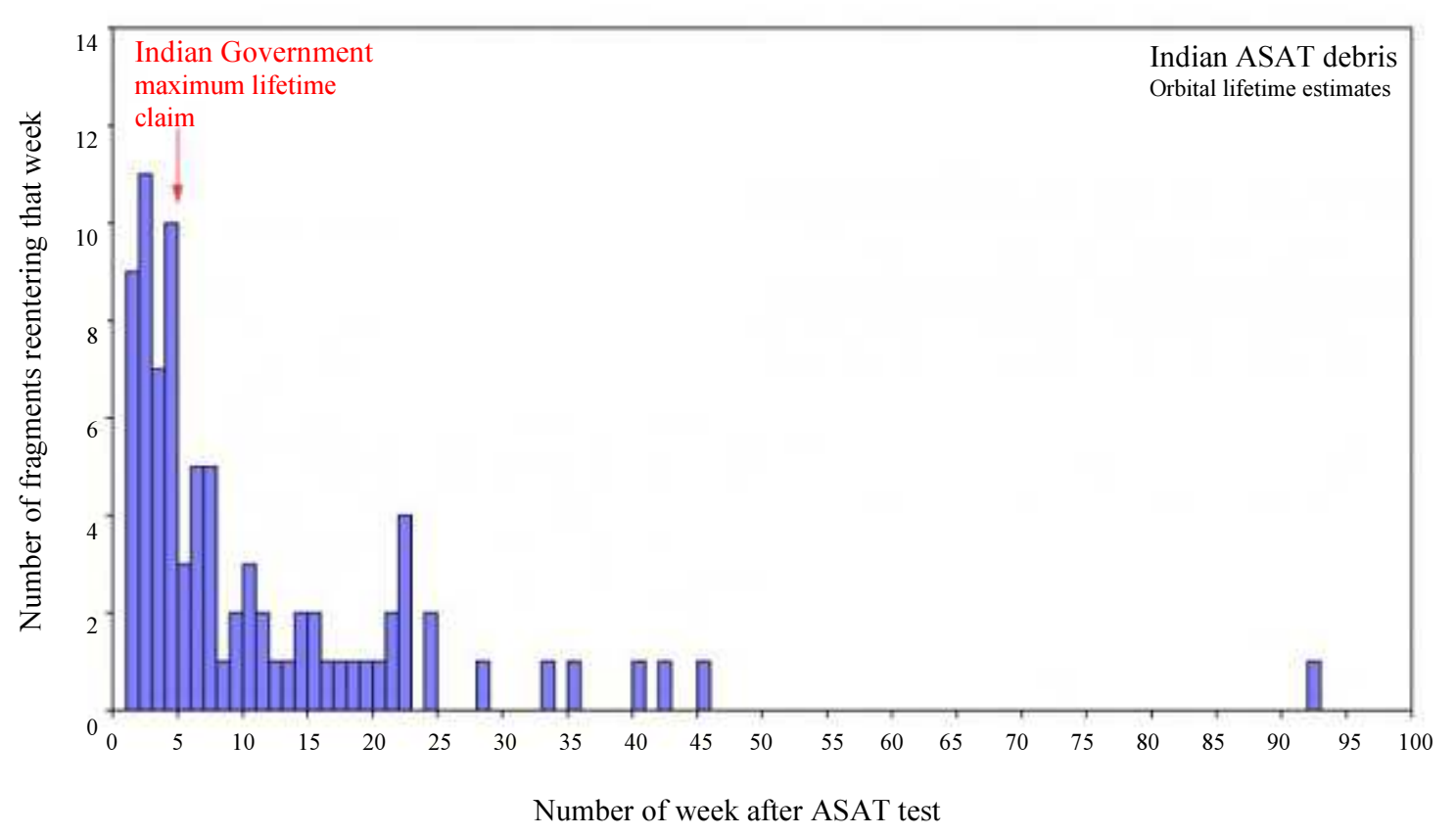

Fig. 11: Orbital lifetime estimation of currently tracked fragments

The U.S. Strategic Commands Joint Force Space Component Command (JFSCC) is also monitoring more than 250 fragments generated with an ASAT. As observed in Fig. 9, the perigees associated with the debris fragments nearby the altitude of ASAT and the apogees spread up to an altitude of $2,250 \mathrm{~km}$. Although, most of the small fragments produced by ASAT have actually re-entered within hours of the test. The graphical representation of the missile's trajectory is shown in Fig. 10. National Aeronautics and Space Administration (NASA) Administrator call the test "unacceptable" and termed ASAT as being a terrible thing. He furthermore reported that it is awful to create an event that sends debris to an apogee well above the orbit of ISS. This type of action is not suitable for continuing the ongoing and future human spaceflights. As per the estimation from the U.S., the impact of small debris on the ISS has increased by $44 \%$ as a result of the test. Moreover, India's test is not to raise the space debris issue. Calculations have mentioned that there surely is no risk to the ISS, other satellites and space objects because the test was conducted far below the station's $400 \mathrm{~km}$ altitude. Whatever the debris generated have decayed and fallen straight back onto the Earth within weeks or months. The orbital lifetime estimation of fragments generated by ASAT test is plotted in Fig. 11. Also, by performing the ASAT test, India has not violated any international legislation or treaty to which it is a party to or any social obligation. Thus, there is no necessity for other space powers to worry about the threat of debris (Marco, 2019).

\section{High Priority for Mission}

India's ASAT mission had been a top-priority classified military project of the century, kept under wraps for almost thirty-one months to become accurate. It had been codenamed as 'Project XSV-1' where SV obviously mean Shakti Vehicle and 1 stood for the very first mission. Merely a six core scientists at DRDO knew regarding the project. For rest of the team, it was exoatmospheric interceptor missile, part of another more substantial Ballistic Missile Defence (BMD) program with specific advancements. The core members of the project were told to maintain privacy about the project immediately after the go-ahead signal from Prime Minister in 2016. The DRDO had been instructed in no uncertain terms that at no point any details about ASAT mission will likely be discussed on general public domain or spoken about. The DRDO authorities were also warned several times officially not to divulge way too many details regarding sensitive strategic missions. Additionally, regular instructions were given to keep the low key on social missions. The government also wanted all ministries, including the Ministry of Defence (MoD) to follow strict guidelines whenever it came to information decimation. Every person in DRDO and also Defence Public Sector Undertakings (DPSUs) was getting supervised and were answerable to precisely what was in their domain. The DRDO scientists were told to pay attention to their work instead of their image building exercises. From September 2018 to March 2019 , the period of half year was essential for the ASAT mission. The DRDO teams were growing in confidence and 
all proven technologies were carefully scrutinized and fault lines are drawn. It had been practically a $24 \times 7$ mission for many scientists. Leaves and short-term duties of those who have been a member of the mission were restricted. For the DRDO, it was not an easy task to mask a mission of such scale with so many scientists and teams involved. It was even tougher to remain under the media radar. The BMD cover well suited as Prithvi Defence Vehicle (PDV) was known to all and hence the mission was officially called PDV-MK II. Even many top officials at DRDO Bhawan in New Delhi were clueless about the ASAT mission. Involvements of the DRDO and ISRO too were kept private and also ISRO officials were not known much about Microsat-R (Anantha, 2019).

\section{Space Laws and Arms Control Concern}

India does not have any intention of getting into an arms race in outer space. The country has continually thought that space can be utilized only for peaceful purposes. India is in opposition to the weaponization of Outer Space and assists international efforts to strengthen the safety and security of space-based assets. India strongly believes that Outer space could be the common heritage of humanity and it is also the responsibility of all spacefaring nations to preserve and promote the benefits flowing from advances made in space technology and its applications for all. India is also an integral part of most of the major international treaties relating to Outer Space. India currently implements several Transparency and Confidence Building Measures (TCBMs) - including registering space objects with the UN register, prelaunch notifications, measures in harmony with the UN Space Mitigation Guidelines, involvement in Inter Agency Space Debris Co-ordination committee (IADC) activities pertaining to space debris management, undertaking Space Object Proximity Awareness (SOPA) and Collision Avoidance Analysis (COLA) and countless international cooperation activities, including hosting the UN-affiliated Centre for Space and Science Technology Education in Asia and Pacific. India is taking part in all sessions associated with the UN Committee regarding the Peaceful Uses of Outer Space. India also supported UNGA resolution $69 / 32$ on No First Placement of Weapons in Outer Space. Equally, India supports the substantive consideration of the issue of Prevention of an Arms Race in Outer Space (PAROS) into the Conference on Disarmament where it has been on the agenda since 1982. The feasible weaponization of space is a subject of significant concern for most of the nations, including India. Regrettably, the space arena has limited globally accepted multilateral treaty mechanisms and such available mechanisms are mostly issue-centric and may not be seen as all-pervasive. Besides, India is a signatory to the 1967 Outer Space Treaty and ratified it in 1982. The treaty forbids only weapons of mass destruction in outer space, not conventional weapons. For the last ten years or more, some efforts have already been made to deal with this issue, for instance, the European Union as well as its International Code of Conduct. India expects to play a role in the foreseeable future in the drafting of international law on avoidance of an arms race in outer space including among other things on the prevention of the placement of weapons in outer space in its capacity being a significant space-faring nation with proven space technology. India is not in violation of any international law or treaty to which it is a Party or any social obligation. India fully supports the formulation of universal and non-discriminatory transparency and confidence-building measure, although such measures have actually limited relevance simply because they typically are not legitimately binding. However, India believes such mechanisms have a useful complementary part and might become an appetizer for the formulation of any future treaty. India has participated actively in the consultations called by the EU since 2012 to talk about a draft Code of Conduct for Outer Space Activities. Resolution 69/32, titled "No First Placement of Weapons on Outer Space" and adopted in the United Nations General Assembly on December 2, 2014, has got the complete support by India. Nevertheless, India feels that there is a need to grow beyond such ideas and decide on a released and legally binding treaty. In this context, India is going to give pay attention to the revised PPWT (Treaty regarding the Prevention of the Placement of Weapons in Outer Space, the Threat or Use of Force against Outer Space Objects) presented by Russia and China in the Conference on Disarmament. There has been a total rejection of this proposal by some significant powers. However, India is associated with the opinion that such ideas have to be discussed under the UN umbrella (MEA, 2019). In August 2018, the UNIDIR proposed three ASAT Test Guidelines. Under the 'No Debris' principle if a nation wants to test ASAT capabilities, they should not produce debris. Under the 'Low Debris' principle, if a nation produces debris during an ASAT test, the test should be performed at an altitude adequately low that the debris will not be longlived. Under the 'Notification' principle nations testing ASATs should inform others of their activities to prevent misperceptions or misinterpretations. It is important to note that these ASAT guidelines would not be a prohibition on the testing of ASATs or their possession. Also, these guidelines are not be intended to interfere with the development of ballistic missile technology or missiles, if they were carried out at sufficiently low altitudes (Ajey, 2019; Daniel, 2018). 


\section{Conclusion}

Since the inception of its space program, India has followed the policy for the utilization of space for socioeconomic development and also this agenda continues to be valid today. At the same time, owing to geopolitical realities, India needs to make sure that its assets in space are protected. India ultimately realizes that space is a significant area for human survival and should not be tinkered with unnecessarily. Modern-day life is utterly dependent on assets in space. India's growth story, scientific and economical, also involves the contributions made by its space agency and space industry. Today, space provides a significant soft-power potential for India and India believes that it is in nobody's interest to weaponize space. The necessity of the hour would be to evolve a rule-based and transparent mechanism for protecting space.

\section{Acknowledgement}

The author would like to thank unknown reviewers for their thoughtful suggestions and comments.

\section{Ethics}

The author declare that there is no conflict of interest regarding the publication of this article.

\section{References}

Ajey, L., 2019. The implications of India's ASAT test. Anantha, M.K., 2019. DRDO's top secret ASAT mission codenamed 'Project XSV-1'.

Covault, C., 2007. Chinese test antisatellite weapon. Aviation Week and Space Technology. McGrawHill Companies, Inc.

Daniel, A.P., 2018. ASAT test guidelines: A viable option to implement TCBMs.

ISRO, 2019. PSLVC44 Launch Brochure. Indian Space Research Organisation.

Marco, L., 2019. Why India's ASAT Test was Reckless.

MEA, 2019. Frequently Asked Questions on Mission Shakti. Ministry of External Affairs, India's AntiSatellite Missile test conducted on 27 March, 2019.

Sheetz, A. Macias and Michael, 2019. Russia succeeds in mobile anti-satellite missile test: US intelligence report. Cnbc.com.

Webb, A., 2008. Joint effort made satellite success possible. US Air Force.

\section{Figures Sources}

Fig. 1: Source: https://spacenews.com/nasa-resumescooperation-with-isro-after-asat-test/

Fig. 2: Source:

https://www.globalsecurity.org/space/world/china/i mages/sc-19-image01.gif

Fig. 3: Source: https://upload.wikimedia.org/wikipedia/commons/9 /96/SM-3_intercepting_NROL-21-20080220.jpg

Fig. 4: Source: https://space.skyrocket.de/img_sat/microsatr_1.jpg

Fig. 5: Source: Author created Image.

Fig. 6: Source: Image captured from the DRDO official video of ASAT Test.

Fig. 7: Source: Image captured from the DRDO official video of ASAT Test.

Fig. 8: Source: https://manage.thediplomat.com/wpcontent/uploads/2019/04/thediplomatfig13_debris_gabbard_diagram.png

Fig. 9: Source: https://thediplomat.com/wpcontent/uploads/2019/04/thediplomatfig14_pogee_distribution_microsat_deb790x476.png

Fig. 10: Source: Image captured from the DRDO official video of ASAT Test.

Fig. 11: Source: https://thediplomat.com/wpcontent/uploads/2019/04/thediplomatfig15_microsat_debris_lifetimepred-790x440.png 